\title{
Participatory design of persuasive technology in a blended learning course: A qualitative study
}

\author{
Monique M. J. Engelbertink ${ }^{1,2}$ - Saskia M. Kelders ${ }^{2,3}$. \\ Kariene M. Woudt-Mittendorff ${ }^{1}$. Gerben J. Westerhof ${ }^{2}$
}

Received: 11 October 2019 / Accepted: 28 February 2020/ Published online: 25 March 2020

(C) The Author(s) 2020

\begin{abstract}
Whereas blended learning can deliver several benefits to students in higher education, their achievement depends on how exactly it is designed. A participatory design is recommendable to try to meet the needs of all stakeholders. The Persuasive System Design-model can be used to motivate students during the online part of the course. In the design there has to be an optimal blend between the different parts of the course. A participatory design is used to design a blended learning course of autobiographical reflection for second year social work students. The blended course was developed in six meetings with a working group, including all stakeholders (students, teachers, instructional designers, educational experts and professionals). Almost all techniques of the first three categories of the PSD-model were used in the design of the blended course. None of the techniques of the fourth category 'Social Support' of the PSD-model were used, mostly because they touch on the personal process of autobiographical reflection. It was considered helpful for teachers to have a protocol that assists them in blending the different parts and this in turn could stimulate students to be engaged in the different parts of the blended learning course. In this study, we found that the participatory design approach may lead to an engaging blended learning course that encourages the use of persuasive technology with an optimal focus on content, target group, context and ethical aspects of the blended course. We suggest adding a new fifth category 'Blended Learning Support'.
\end{abstract}

Keywords Participatory design · Blended learning · Persuasive technology $\cdot$ Reflection · Higher education

Monique M. J. Engelbertink

m.m.j.engelbertink@saxion.nl

Extended author information available on the last page of the article 


\section{Introduction}

Blended learning is a trend within higher education. It involves the use of Faceto-Face Classes (FTFC) supplemented with online learning technology where this can be used synchronously or asynchronously (Garrison and Kanuka 2004; Kiviniemi 2014; Lam 2014; López-Pérez et al. 2011). In this article we focus on asynchronous application of blended learning. Blended learning combines the benefits of FTFC and eLearning in order to create a motivating, as well as efficient, learning environment (de Jong et al. 2014; Lam 2014; Søraker 2015; Uğur et al. 2011; Vo et al. 2017). Although blended learning challenges the selfregulation skills of students (Monk et al. 2020), blended learning might have two promising advantages: it provides a blended learning approach which students prefer, and it can lead to better learning outcomes.

Students have expressed eminently positive views regarding blended learning and that they prefer it to traditional lessons alone (Kiviniemi 2014; López-Pérez et al. 2011; Uğur et al. 2011). Online courses allow the students to gather knowledge at their own pace, with time to clarify any difficulties they have experienced in later FTFC (Kiviniemi 2014; Lowell Bishop and Verleger 2013). An additional benefit of FTFC to an online course is the social interaction it provides (Uğur et al. 2011). Teachers are able to motivate their students in blended learning, in turn resulting in lower dropout rates in comparison to eLearning (López-Pérez et al. 2011).

Moreover, blended learning seems to offer an effective and efficient learning environment, eliciting greater learning outcomes (de Jong et al. 2014; Garrison and Kanuka 2004; Kiviniemi 2014; López-Pérez et al. 2013). Regarding learning outcomes, some studies say that blended learning exceeds the traditional FTFC approach (Bernard et al. 2014; Kiviniemi 2014; López-Pérez et al. 2011; Vo et al. 2017). The latter three studies indicate that due to blended learning the involvement of students is being increased, that the students' learning process is being improved because of the online activities and that students are spending more hours on learning, and these factors together have a positive effect on their course grades. On the other hand, Monk et al. (2020) indicate that students' grades do not increase through blended learning, other factors such as the grade for the test before and gender (in favor of men) were found to have an effect. From the many questions that still exist to arrive at a good analysis of all the active factors within blended learning, (Keengwe and Kang 2013) indicates that much research is still needed that combines traditional conceptual frameworks with qualitative research. Teachers play an important role in the design and implementation of online learning environments to ensure students fully benefit from the potential advantages of blended learning (McNaught et al. 2012; SantaRosa 2012). Schneider and Preckel (2017) conducted a systematic review of meta-analyses on factors associated with achievement in higher education. The most important factor illustrated, that is under the control of teachers, was the amount of time and effort put in to preparing and designing the course, which related to the specific learning goals, content and student population. This is particularly key in blended learning, as designing and implementing an engaging blended learning environment is a rather complex task, with many factors 
potentially being overlooked (Bernard et al. 2014; Ma et al. 2015). There is no 'one size fits all' solution; the design 'depends on [the] content and learning objectives, [as well as the] target group of participants and available facilities' (de Jong et al. 2014, p. 287). Although blended learning has several benefits to students in higher education, its efficiency predominately depends on the exact design of a blended learning course. This paper discusses the design of a blended learning course in a participatory design that involves various stakeholders (such as students, teachers, educational experts and ICT specialists). In this way, we hope to fulfill the needs of all stakeholders. We analyze the use of persuasive technology (PT) to create a blended learning environment that motivates students, further examining how different elements of the course can be blended in an optimal way.

\subsection{Persuasive technology}

It is indisputable that students need to engage with an online environment to be able to make optimal use of its content (Bernard et al. 2014; Henrie et al. 2015; Ma et al. 2015; Santa-Rosa 2012; Van Gemert-Pijnen et al. 2014). However, student engagement can be difficult with multiple factors potentially impeding engagement in blended learning (Holley and Oliver 2010). PT is technology that can be used for instance in an online course to strengthen, change or influence the individual's behavior and attitudes avoiding use of coercion or deception (Fogg 2003; Oinas-Kukkonen and Harjumaa 2009). It is often used in areas of blended healthcare, which are found online, encouraging clients to engage with their treatment (Kelders et al. 2015; OinasKukkonen and Harjumaa 2009). PT additionally has potential within the educational field, aiding students' engagement with their learning. However, its use is still relatively new in this field (Behringer et al. 2013; Burri Gram-Hansen and Ryberg 2013; Devincenzi et al. 2017; Fogg 2003; Mintz and Aagaard 2012; Ng et al. 2016).

The Persuasive Systems Design-model (PSD-model) can be used to develop an engaging blended learning environment (Oinas-Kukkonen and Harjumaa 2009). This PSD-model includes four technological support categories: primary task support; dialogue support; system credibility support; and social support (see Table 1). In total, these categories contain 28 different techniques which increase persuasiveness. An example of a technique used in the 'primary task support'

Table 1 Persuasive Systems Design-model (Oinas-Kukkonen and Harjumaa 2009)

Persuasive Systems Design-model

\begin{tabular}{|c|c|c|c|}
\hline Primary task support & Dialogue support & Credibility support & Social support \\
\hline $\begin{array}{l}\text { Reduction, tunneling, } \\
\text { tailoring, } \\
\text { personalization, } \\
\text { self-monitoring, } \\
\text { simulation, rehearsal. }\end{array}$ & $\begin{array}{l}\text { Praise, rewards, } \\
\text { reminders, } \\
\text { suggestion, } \\
\text { similarity, liking, } \\
\text { social role }\end{array}$ & $\begin{array}{l}\text { Trustworthiness, expertise, } \\
\text { surface credibility, } \\
\text { real-world feel, authority, } \\
\text { third-party, verifiability }\end{array}$ & $\begin{array}{l}\text { Social learning, social } \\
\text { comparison, normative } \\
\text { influence, social } \\
\text { facilitation, cooperation, } \\
\text { competition, recognition }\end{array}$ \\
\hline
\end{tabular}


category was personalization, as the computer may speak to the student stating their name. In the 'dialogue support' category it may generate rewards, where students are provided with symbols - such as a star, medal, thumb - as an act of encouragement upon completing part of an online module. The 'system credibility support' category has a real-world feel to it, in that students receive information about the author of the course. This can facilitate a sense of reassurance and comfort for the students that there is a legitimate person behind the course. Finally, a technique used in the 'social support' category was social comparison. This would allow students, for example, to view the other student's progress online. However, to use PT appropriately and successfully in a blended course online, the designers must be fully aware of the context, the content and the ethical aspects (Burri Gram-Hansen and Ryberg 2013; Oinas-Kukkonen and Harjumaa 2009). Our design approach will be further discussed in the following paragraph, addressing and gaining a more detailed understanding of these factors.

\subsection{Participatory design}

An approach that may assist in creating an engaging blended learning environment, with the appropriate use of PT, is a participatory design. A participatory design is a specific form of human-centered design, and an interdisciplinary approach used to develop ICT products that try to fulfill the needs of all participants (Bratteteig and Wagner 2016; Ruland et al. 2008; Sanders and Stappers 2008; Simonsen and Hertzum 2012). Research has shown that human-centered designs have demonstrated a positive effect on both user satisfaction as well as fulfilling the user's values and needs (Bano and Zowghi 2015; Van Gemert-Pijnen et al. 2011).

Participatory design implies that different stakeholders, including designers, researchers, teachers and students, are partners within the design process. Due to the different stakeholders, a participatory design therefore has the character of negotiating, mediating and seeking consensus to reach a decision (Booker and Goldman 2016). Several authors have advocated involving end users in a participatory design within the educational field for several reasons: to enhance partnership and equality among all participants (Booker and Goldman 2016; Bovill 2014); to use expertise and learn about the experience of students (Blau and Shamir-Inbal 2018; Könings and McKenney 2017; Santa-Rosa 2012) and teachers (Cha and Ahn 2019); to support students in their learning of participatory design practices (Frauenberger et al. 2015); and to develop feasible materials and activities to optimize the implementation in the specific educational field (Blau and ShamirInbal 2018; Cober et al. 2015; Song and Oh 2016). As a result of a participatory design, it can demonstrate improved engagement by different participants (Blau and Shamir-Inbal 2018; Bovill 2014; Cober et al. 2015) and overall improvement of student performance (Bovill 2014).

\section{Research questions}

In short, a participatory design of a blended course may contribute to the fulfillment of the needs of students, teachers and other stakeholders. PT may be an element that 
contributes to the engagement of students. In the long term, the combination of a participatory design and PT techniques may lead to a successful implementation of the blended learning course, possibly enhancing the motivation of students and their learning outcomes. The context of this blended learning course is an autobiographical reflection, used to strengthen the professional identity of social work students (Bachelor's degree), which will be explained in the setting of our method section.

Two research questions will be addressed in this design study:

1. Which of the PT techniques of all four categories of the PSD-model are suitable to apply in the online element of the blended learning method of autobiographical reflection for second-year social work students?

2. What are the needs of students and teachers according to the stakeholders to achieve an optimal blend between the FTFC and the online element of the course?

\section{Method}

\subsection{Design}

Based on a participatory design approach, six meetings with the working group, made up of stakeholders (see the participants section), were held in which the design of the blended course was discussed. Each meeting took approximately $2 \mathrm{~h}$ and the meetings took place over a period of 6 months. The number of meetings was determined based on the content, as we wanted to discuss several subjects in an iterative process, and on the available time before the lessons would commence where the course would be tested. The online part of the course was designed by the first author and an instructional designer using Articulate Storyline, which is an interactive eLearning software. The time investment by the first author amounted to 3 days per week over a period of 4 months and to $3 \mathrm{~h}$ per week for the instructional designer.

\subsection{Setting}

The study took place in the School of Social Work of Saxion, University of Applied Sciences. The School of Social Work decided to develop a course, named 'Autobiographical reflection', for second-year social work students which would contribute to the development of their professional identity. Earlier experiences, which were positive overall, using a similar course for fourth-year students of different educational programs inspired this study's aims. That course was part of a minor degree, which focused on exploring philosophical questions on a personal and professional level (Engelbertink 2015a). The course consisted of FTFC, peer groups and homework with the use of the self-help book 'The Stories We Live By' (Bohlmeijer and Westerhof 2010). This method was developed for middle-aged and older people to review their life, in order to alleviate symptoms of depression and increase a feeling of well-being. The method has proven to be effective for middle-age and older people in both a face-to-face and online setting (Korte et al. 2012; Lamers et al. 2015; Westerhof et al. 2017). After seven FTFC of one-and-a- 
half hours each, the students came together independently in peer groups (also for one-and-a-half hours) to interview each other discussing the topics that were included in their homework. This way, the students supported one another in the transition from FTFC to the homework element of the course. In order to ensure a high standard of autobiography, a time investment of $2 \mathrm{~h}$ per week was requested to be spent on the online course. Additionally, there were also students on the course who spent $4 \mathrm{~h}$ doing their weekly homework.

This initial course was the starting point for the current study. A new blended course was developed based on three core elements. The first constituted new technological developments in the educational field. Saxion started to endorse the vision that ICT can have a key function in organizing personal and adaptable education (Bleumink 2016). The online course 'The Stories We Live By' (Westerhof et al. 2017), based on the book with the same name (Bohlmeijer and Westerhof 2010), was used in the initial course and was the foundation for the new online element of the course for students. Secondly, the original intervention was primarily aimed at decreasing symptoms of depression in middle-aged and older people. However, it was not tailored to the target group 'students'. Thus, the new course had to be written from the perspective of second-year social work students and needed to have a professional aim that aligned with their phase of education (awareness and reinforcement of the professional identity of social work students) (Engelbertink 2015b). Thirdly, students found it difficult to put in the time and effort to complete their homework. Students had to write their autobiography which took them, on average, approximately $2 \mathrm{~h}$ per week over a course of 6 weeks. At times, some students would forget to do their homework and some wrote their autobiography after the course, meaning they were unable to actively participate during the FTFC. Moreover, some students worked on their homework for only half an hour per week, thus preventing the high quality of work that teachers expected. Social work teachers expressed, from their own experiences with the students, that second years were less likely to be motivated to do their homework than fourth-year students. To facilitate students' motivation to complete their homework and autobiographies over a weekly two-hour period, the online module must be interactive and encouraging. PT could support students in completing their homework in an effective and cooperative way.

\subsection{Participants}

The working group of stakeholders $(N=17)$ consisted of (former) students, teachers, ICT specialists, educational experts, and social workers. All participants were female, with the exception of two male teachers. The students were recruited via an email from their career supervisor. In this e-mail, students were asked if they were interested in participating in the development of a blended learning course dealing with autobiographical reflection. There was no financial compensation for the students to participate. The students therefore made use of their free time in their curriculum and were rewarded with a course credit. A former student who participated was asked to do so by the first author, since she had participated in the first author's lesson on autobiographical reflection and had a positive, critical attitude towards the method. The social workers were recruited from the network by the first 
author on the basis of their knowledge about reflection by social work interns. The teachers were also recruited by the first author due to their experience in teaching autobiographical reflection. In addition, she specifically asked a male teacher in order to achieve a more balanced male to female ratio. The educational experts and the IT specialists were professionals affiliated with the academy where the research took place. In case this was needed, their manager gave the professionals consent to participate. The researcher (first author) coordinated the working group and kept minutes of each of the six meetings.

Below is an overview of the characteristics of the participants:

- 4 second-year Bachelor students in social work. Age: 19, 19, 20, and 21 years.

- 1 former student who participated in the earlier course in the Minor. Bachelor degree. Age: 25.

- 2 teachers who taught the previous course in the Minor, Master degree and Bachelor degree. Age: 41 and 50.

- 2 teachers second-year social work. Bachelor degree and Master degree. Age: 37 and 58.

- 2 ICT specialists (one Instructional Designer and one policy officer ICT). Both Master degrees. Age: 26 and 37.

- 1 developer part-time education. Master degree. Age: 55 .

- 2 educational experts. Both Master degrees. Age: 49 and 55.

- 3 social workers (specialism: secondary school education; youth revalidation; coaching professionals). All Bachelor degrees. Age: 35, 43 and 59.

\subsection{Materials}

Table 2 presents an overview of the content from the six meetings, stating their aims and working methods. During the first meeting participants were informed about PT

Table 2 Content of the participatory working group

\begin{tabular}{|c|c|c|}
\hline Meeting & Aim & Working method \\
\hline \multirow[t]{2}{*}{1} & $\begin{array}{l}\text { Having the interest and engagement of the } \\
\text { participants to a blended learning course } \\
\text { autobiographical reflection with the use of PT. }\end{array}$ & SWOT analyze of adapting PT in online part \\
\hline & Insights in the SWOT's of the blended course. & $\begin{array}{l}\text { SWOT analyze of applying autobiographical } \\
\text { reflection by second year social work } \\
\text { students. }\end{array}$ \\
\hline 2 & $\begin{array}{l}\text { Determine the goals, rewriting the texts and testing } \\
\text { paper based prototype (content, including } \\
\text { screenshots) }\end{array}$ & Testing paper based prototype \\
\hline 3 & Determine the PT & Description PT \\
\hline 4 & Testing working prototype (content, lay-out) & Testing working prototype \\
\hline 5 & Testing working prototype (PT, blended learning) & Testing working prototype \\
\hline 6 & $\begin{array}{l}\text { Testing final prototype behind the computer } \\
\text { (content, lay-out, PT and blended learning) }\end{array}$ & Testing final prototype \\
\hline
\end{tabular}


and autobiographical reflection. The participants made two SWOT analyses (Strengths, Weaknesses, Opportunities, Threats): one about using PT in the online part of the blended course, and the other regarding applying autobiographical reflection to secondyear social work students. The participants wrote their comments on several sticky notes. All sticky notes were mounted on a flipchart and then discussed.

During the second meeting, the minutes of meeting 1 were evaluated and adjusted where necessary. Next, the goals of the course 'autobiographical reflection' for secondyear social work students were determined. Lastly, the participants read the text from the online version of the course 'The Stories We Live By' (Authors). The first author made a paper-based prototype based on the existing online course. The working group members then gave input and feedback on the text and the screenshots. The four second-year social work students rewrote the text after session 2, which accommodated the wishes of the working group in making it suitable for the target group of students, with the goal of developing their professional identity, e.g. language, appropriate student examples, and length of the text of each theme.

For the third meeting, the first author made a description of the 28 techniques of the PSD-model and how each technique could be applied in the online section. See Tables 3, 4, 5, and 6 in the results section for the descriptions of the various techniques as submitted to the working group. The participants discussed the techniques and then communicated any input and feedback in pairs.

In the fourth and fifth meeting, the working group tested a working prototype of the online aspect of the course on a computer. These prototypes were developed through the working group's input during previous meetings. The feedback on the prototype was given on paper by the participants in pairs or individually. They focused on: 1) content; 2) lay-out; 3) PT; 4) blended learning (how the online element can align with the FTFC).

During the final meeting with the working group, participants tested the final prototype with the complete user interface in pairs or individually. The prototype was distributed by Articulate Storyline throughout the Learning Management System Blackboard, and published to access through a web browser. Therefore, the users were led to a new webpage where the online element was displayed. All of the data entered by the students would be stored in the browser for 90 days, and then erased. The working group members tested the prototype and made comments on any mistakes that caught their attention. Similar to meetings four and five, they focused on: 1) content; 2) lay-out; 3) PT; 4) blended learning. Additionally, they answered some prespecified questions. Exemplar questions included: What do you think of the number of assignments (content); What do you think of the colors? (lay-out); What do you think of the icons that can be seen (star, thumb, medal, etc.) (PT); How can the teachers connect the lessons to the online module? (blended learning).

\subsection{Procedure}

In each meeting, an alternative date was set for respondents who were unable to attend the initial meeting. The first author chaired all of the meetings and coordinated the design of the course. An instructional designer and the first author created and altered the technical design of online aspects of the course using Articulate Storyline. It should be noted that this instructional designer was not part of the working group due to a staff change. 


\subsection{Data analysis}

The first two meetings were audio recorded. Minutes were noted and at the following meeting presented to the working group to check, giving the group an opportunity to communicate their feedback expressing their opinions or views. Throughout the other four meetings, the participants gave written feedback on several of the working prototypes in pairs or individually. The minutes and written feedback were analyzed and subsequently used to design the online element by the first author and the instructional designer. For this study, the minutes and written feedback were coded on the basis of four topics: course content, lay-out, PT and blended learning. Coding was done both deductively (based on the topics above, and on pre-specified questions), as well as inductively (categorizing the explanations of the members of the working group). The minutes were used to keep track of the improvements that were desired and to see if the wishes of all stakeholders could be granted and if wishes were not contradicted during the meetings. Summaries of the coding are presented in the results.

\section{Results}

Before we present the results, stating the preferences of the working group regarding the various PT techniques (research question 1) and blended learning (research question 2 ), first we shall briefly discuss the content and lay-out of the online course, as this partially determined the choice of which technique was used. As mentioned before, the content was tailored, with the course being rewritten, in order to develop the social work students' professional identities.

\subsection{Content and lay-out}

The first step that the working group took involved formulating a SWOT analysis, which applied autobiographical reflection to second-year social work students. The SWOT analysis identified the autobiographical reflection's potential, but also highlighted the need for support during the course for both students and teachers. Participants considered it very important that confidentiality was guaranteed while the students wrote their autobiography online.

During the second meeting, the working group read the text from the online version of the course, which contained six themes. Each theme of the course involved a writing part, where students were asked to express any positive and negative thoughts and memories they had experienced in their life, including factors related to their identity. Additionally, in the reflection task, students evaluated their (difficult) memories. In general, the working group found the assignments well-suited and relevant for students, with some adjustments being made in the reflection aspect of the course. The working group also found it desirable that the text was written from the living and experiential world of the students. With the written feedback from the working group members after the second meeting, the four second-year students rewrote the text of the six themes. This editing required adjustments in language, and examples from students' lives; these will not be described in detail to keep this paper succinct. The final editing was implemented by the first author. 
During the final three meetings, the working group made suggestions for the lay-out, including alterations to: the shape and size of the rewards, the icons, the use of color, the font, the text frames and the pictures. The participants found the photo of the existing online course depressing, since it was a black and white picture of a bare mountain landscape, leading to the choice of a more neutral image which was more relatable to the goal of the course (writing and reflecting). In Appendix 1, several screenshots are included to give an impression of what the lay-out looked like in the online element of the blended course.

\subsection{PT techniques}

During the first meeting, the working group formulated a SWOT analysis to apply PT within the context of the blended learning course's autobiographical reflection. By using PT, the working group predicted that second-year social work students would become motivated and that the techniques could shape personalized learning, so that students received customized process guidance. The techniques were expected to prevent individuals from dropping out while writing their autobiography, to fit the world of young people and to establish a connection with fellow students. The challenges identified by the participants in the working group were on learning attitudes (resistance of students against digital working, PT becoming a 'habit', diminishing intrinsic motivation of students) and costs (developing the course was expensive and time-consuming). The participants wondered whether the course would be sufficiently personalized given the diversity of students.

In order to minimize these challenges, the working group expressed their belief in the importance of technology in serving as a supporting element of the FTFC, and never becoming a goal in itself. It should always be the student's responsibility for writing their autobiography. The working group did not want extrinsic motivation to disrupt intrinsic motivation. The techniques of the PSD-model should be applied in such a way that the external stimuli reinforce the content (and not just determine the motivation of the student). Students and ICT specialists saw more opportunities to apply PT, expressing a higher need for it, than teachers and professionals. Students and ICT specialists furthermore had more experience with previous online courses compared to teachers and professionals, so were able to bring this experience to the workgroup. As an example, one of the second-year students indicated that she had followed an online course in the previous year in which she could see exactly how far she was in the course due to a progress bar. She found this factor a highly motivational aspect of the course.

During the third meeting, the working group gave feedback on the description of the PT techniques and how they could be used in the online course (see Tables 3, 4, 5, and $6)$.

The working group considered all of the techniques from the first category 'primary task support' as encouraging and motivating for the students. Consequently, each technique was applied in the online element of the blended course, except for an aspect of the 'personalization' technique, where students could design part of the online course themselves. Due to limitations elicited by the software used, this could not be implemented. Table 3 displays an overview of the working group's preferences of PT and the choices that were made for the design of the prototype. 
Table 3 Primary task support and design prototype

\begin{tabular}{|c|c|c|c|}
\hline \multicolumn{2}{|c|}{1 Primary task support } & \multirow{2}{*}{$\begin{array}{l}\begin{array}{l}\text { Preferences } \\
\text { working } \\
\text { group }\end{array} \\
\text { Motivating }\end{array}$} & \multirow{2}{*}{$\begin{array}{l}\begin{array}{l}\text { Design } \\
\text { prototype }\end{array} \\
\text { Applied }\end{array}$} \\
\hline Reduction & Dividing assignments into themes. & & \\
\hline \multirow[t]{2}{*}{ Tunnelling } & Guiding students step-by-step through the assignments. & Motivating & Applied \\
\hline & $\begin{array}{l}\text { Students can't go on with the next theme if they did not } \\
\text { finish the previous one. }\end{array}$ & Motivating & Applied \\
\hline Tailoring & $\begin{array}{l}\text { Students can choose from assignments or information. } \\
\text { Applied: choosing information. }\end{array}$ & Motivating & Applied \\
\hline \multirow[t]{2}{*}{ Personalisation } & Computer speaks to students with their own name. & Motivating & Applied \\
\hline & $\begin{array}{l}\text { Students can design the online course by themselves, for } \\
\text { example, choosing their own background photo, adding } \\
\text { a motto. }\end{array}$ & Motivating & $\begin{array}{l}\text { Not applied due } \\
\text { to the software }\end{array}$ \\
\hline Self-monitoring & Students can see their own progress. & Motivating & Applied \\
\hline Simulation & $\begin{array}{l}\text { Students are reminded during the assignments what these } \\
\text { can give them. }\end{array}$ & Motivating & Applied \\
\hline Rehearsal & Methods or techniques come back repeatedly. & Motivating & Applied \\
\hline
\end{tabular}

The techniques from the second category 'dialogue support' were also considered as motivational for students (see Table 4). However, the working group stressed that the techniques 'praise' and 'rewards' must be used to an appropriate extent, to prevent a learning environment that is dominated by extrinsic motivation. There was doubt among some teachers and professionals whether the right level of praise and reward could be found within the design. By repeatedly showing and discussing the applications of the praise and reward techniques, most participants agreed on the right frequency. 'Reminders' were applied in order to prompt students to complete their

Table 4 Dialogue support and design prototype

\begin{tabular}{|c|c|c|c|}
\hline \multicolumn{2}{|c|}{2 Dialogue support } & \multirow{2}{*}{$\begin{array}{l}\text { Opinion } \\
\text { working group }\end{array}$} & \multirow{2}{*}{$\begin{array}{l}\begin{array}{l}\text { Design } \\
\text { prototype }\end{array} \\
\begin{array}{c}\text { Applied } \\
\text { well dosed }\end{array}\end{array}$} \\
\hline Praise & $\begin{array}{l}\text { Students receive digital rewards such as compliments, } \\
\text { digital awards or applause. }\end{array}$ & & \\
\hline Rewards & $\begin{array}{l}\text { Students see pictures/symbols, like a star, medal, thumb } \\
\text { when they complete a part of the online module. }\end{array}$ & $\begin{array}{l}\text { Motivating } \\
\text { well dosed }\end{array}$ & $\begin{array}{l}\text { Applied } \\
\text { well dosed }\end{array}$ \\
\hline Reminders & Students receive reminders for making online assignments. & Motivating & Applied \\
\hline Suggestions & Students can read tips for making the assignments. & Motivating & Applied \\
\hline Similarity & Students can read example stories from former students. & Motivating & Applied \\
\hline Liking & The lay-out is attractive. & Motivating & Applied \\
\hline Social role & $\begin{array}{l}\text { Students can communicate online with fellow students } \\
\text { and teachers. }\end{array}$ & Motivating & $\begin{array}{c}\text { Not applied } \\
\text { due to the } \\
\text { software }\end{array}$ \\
\hline
\end{tabular}


Table 5 System credibility support and design prototype

\begin{tabular}{|c|c|c|c|}
\hline \multicolumn{2}{|c|}{3 System credibility support } & \multirow{2}{*}{$\begin{array}{l}\text { Opinion } \\
\text { working group } \\
\text { Motivating }\end{array}$} & \multirow{2}{*}{$\begin{array}{l}\text { Design } \\
\text { prototype }\end{array}$} \\
\hline Trustworthiness & The online course exudes reliability and credibility. & & \\
\hline Expertise & The online course exudes expertise and professionalism. & Motivating & Applied \\
\hline Surface credibility & $\begin{array}{l}\text { The online course must look competent and good at first } \\
\text { sight. E.g. information about privacy policy. }\end{array}$ & Motivating & Applied \\
\hline Real-world feel & $\begin{array}{l}\text { Information about the author and developer of the method / } \\
\text { online course gives the feeling that there is a real world } \\
\text { behind the method. }\end{array}$ & Motivating & Applied \\
\hline Authority & $\begin{array}{l}\text { Is the method /online module associated with a quality } \\
\text { mark? Are there national requirements about the method / } \\
\text { online module? }\end{array}$ & Motivating & Applied \\
\hline $\begin{array}{l}\text { Third-party } \\
\text { endorsements }\end{array}$ & $\begin{array}{l}\text { Is information about the method / online module available } \\
\text { via external sources (other websites or other teaching } \\
\text { methods)? Controllable? Is the method embedded in } \\
\text { another method? Does it link with other methods? }\end{array}$ & Neutral & Applied \\
\hline Verifiability & The sources that the online course uses can be checked. & Motivating & Applied \\
\hline
\end{tabular}

homework on a weekly basis. The students were reminded via email from their teacher to finish their homework for that week. The Articulate Storyline software does not provide the possibility to communicate between users. Due to this software limitation, the 'social role' technique was unable to be implemented, despite the members of the working group finding this technique motivating.

With the exception of one, all of the other techniques within the third category 'System Credibility Support' of the PSD-model were further considered motivating for the students (see Table 5). As the online element of the blended course was based on an evidence-based method and further developed by the working group, it would be provided in Blackboard. Therefore, 'surface credibility', 'real-world feel' and 'authority' should be guaranteed according to the working group. The working group stated that 'third-party endorsements' were a neutral technique that would not contribute directly to the students' motivation. The working group argued that students were not susceptible to this. However, in the colophon of the online course, it was mentioned that the method was based on Authors' book.

In contrast to the other three categories of the PSD-model, the working group had a more differentiated view of the techniques in the fourth category 'Social Support' (see Table 6). Based on a democratic process, the working group decided that they did not want to apply the techniques 'social comparison', 'normative influence', 'social facilitation' and 'competition', due to the personal process that students went through when they reflected in their autobiography. These techniques would stimulate a competitive group process, which would be undesirable, according to the professionals in the working group. Some of the students and ICT specialists did notice opportunities in which they could apply these techniques, which would aid stimulation in the students, in the online element of the course. However, the majority of the working group stated that autobiographical reflection was an individual process, and the quality of the process must be a central factor. Social learning and recognition were two techniques used within the 'social support' category that could be 
Table 6 Social support and design prototype

\begin{tabular}{|c|c|c|c|}
\hline 4 Social support & & $\begin{array}{l}\text { Opinion } \\
\text { working } \\
\text { group }\end{array}$ & Design prototype \\
\hline Social learning & $\begin{array}{l}\text { Students gain insight into what the online course } \\
\text { delivers to others (what has it brought them in } \\
\text { their development?). }\end{array}$ & Motivating & $\begin{array}{l}\text { Not applied due } \\
\text { to the software }\end{array}$ \\
\hline Social comparison & $\begin{array}{l}\text { Students can view the progress of other students } \\
\text { online. }\end{array}$ & $\begin{array}{l}\text { Not } \\
\text { motivating }\end{array}$ & Not applied \\
\hline $\begin{array}{l}\text { Normative } \\
\text { influence }\end{array}$ & $\begin{array}{l}\text { Use peer pressure to change behaviour. Show a } \\
\text { graph of students who have completed their } \\
\text { homework every week or completely } \\
\text { (disadvantage if the majority did not make the } \\
\text { assignment, the student thinks: oh they have not } \\
\text { finished it yet). }\end{array}$ & $\begin{array}{l}\text { Not } \\
\text { motivating }\end{array}$ & Not applied \\
\hline Social facilitation & $\begin{array}{l}\text { Receive online feedback from fellow students and } \\
\text { teachers. }\end{array}$ & $\begin{array}{l}\text { Not } \\
\text { motivating }\end{array}$ & Not applied \\
\hline Cooperation & $\begin{array}{l}\text { Collaborate with fellow students in the online } \\
\text { course. }\end{array}$ & Motivating & $\begin{array}{l}\text { Not applied But } \\
\text { facilitated in } \\
\text { peer group }\end{array}$ \\
\hline Competition & $\begin{array}{l}\text { In addition to natural drive to work together, people } \\
\text { also have a natural drive to compete with each } \\
\text { other. You can compete per class or per } \\
\text { subgroup who fully completed the homework in } \\
\text { the time that precedes it. }\end{array}$ & Demotivating & Not applied \\
\hline Recognition & $\begin{array}{l}\text { Example stories of students who have also } \\
\text { achieved the behaviour. E.g. by reading fictive or } \\
\text { anonymous quotes from students who have also } \\
\text { completed the teaching method (both focused on } \\
\text { autobiographical reflection and focused on } \\
\text { persuasive technology). }\end{array}$ & $\begin{array}{l}\text { Motivating If } \\
\text { it is not } \\
\text { public }\end{array}$ & Not applied \\
\hline
\end{tabular}

used via the online course, according to the working group. Nonetheless, as mentioned before, the Articulate Storyline software did not provide the possibility for communication between its users, resulting in the social learning technique not being implemented. Further, the working group did not want to use the technique of recognition publicly (for example: selecting the 'student of the week' on the basis of who completed their homework on time, see Oinas-Kukkonen and Harjumaa (2009)). They preferred to add fictive examples of stories by students who achieved the behaviour. This made recognition comparable to the application of the technique 'similarity' (Category Dialogue Support), resulting in recognition being abandoned by the working group. Lastly, the working group considered the technique 'cooperation' as motivating, and through evaluation figured that it would be used best within peer groups as part of the blended course. In these groups, peers collaborated with one another via interviews regarding their life stories in preparation for the online course. This technique was not implemented within the online element of the course; however, it was used within the peer group. Thus, strictly speaking this cannot be described as 'persuasive technology'.

Several PT techniques which were applied in the online course are displayed via screenshots in Appendix 1. 


\subsection{Blended learning}

The working group discussed how the three parts (the FTFC, the peer group and the online element) of the blended learning course could merge in order to strengthen one another. During meetings 5 and 6 with the working group, the participants stated that it was important that teachers followed a protocol assisting them in combining the three factors. According to the working group, the protocol should be as follows: within the FTFC (except for the first lesson) the lecturer would start their discussion regarding the previous week's homework. The students were also able to share their homework output with time being allocated for questions to be asked. After each theme was evaluated online, there was a request given that students were to bring (some of) their assignments to the FTFC. At one particular FTFC, the students were required to bring a specific assignment to be discussed. This assignment dealt with several of the components associated with the students' professional identity. As this subject was related to the professionalism of students, it was decided that the assignment would be discussed at the FTFC. According to the teachers, at FTFC meetings it was considered essential that students shared their homework, as it would facilitate more efficient learning by analyzing and evaluating each other's autobiographic reflections. When teachers demonstrated an interest in each student's homework assignment, it provided them with encouragement and motivation to continue working on their homework each week. Similarly, according to the students of the working group, when their teacher did not discuss their homework with them, it resulted in students feeling unmotivated. Secondly, it was important that the students' experiences within their peer group were discussed. The students were motivated by their teacher to reflect on the discussions that took place during the peer group meeting, and what the added value was. Thirdly, the following week's theme, homework assignment (including when the peer group would meet), as well as encouragement from the teachers were discussed. This protocol in turn ensured an optimized blended learning process, argued by the working group. Although advantages were evident when the students expressed their life stories to one another, the working group wanted to ensure student confidentiality. Therefore, the students were able to choose if, or what, they wanted to share about their lives with their fellow peers and teachers at the FTFC meetings. After the sixth working group meeting, the first author wrote a manual for the teachers based on the discussions of the working group. It contained instructions which were specific to each lesson, the integration of each peer groups' experiences, and their written autobiographies (which emerged from the online module) with the FTFC.

\section{Conclusion and discussion}

This study used a participatory design approach to develop a blended learning course that attempts to fulfills the needs of all stakeholders, by using appropriate Persuasive Technology (PT) to motivate students and that is trying to achieve an optimal blend between the different parts of the blended learning course.

In order to answer the first research question - "which of the PT techniques of all four categories of the PSD-model are suitable to apply in the online element of the blended learning method of autobiographical reflection for second-year social work students?" - it became evident that almost all of the techniques which were related to the first three categories of the PSD- model were considered suitable to apply to the 
design of the blended learning course. However, an interesting finding was that techniques, such as 'rewards' and 'praise' (both in category 'Dialogue Support'), should be used appropriately to stimulate the intrinsic learning process according to the working group. The participatory design approach contributed to finding the appropriate frequency of each of the techniques through its iterative process. None of the techniques from the fourth category, 'Social Support', of the PSD-model were used. The working group expressed the importance that students were able to complete and reflect on their work at their own pace, avoiding stressful deadlines. Several of the techniques from the 'Social Support' category ('social comparison', 'normative influence', 'social facilitation' and 'competition') were not implemented, as they were found to be in conflict with the personal nature of the autobiographic reflection process. The specific process which was used in order to reflect each student's life story was characterized by Spector-Mersel (2016) as a process of temporal distance and a holistic view towards life experiences. This was in sync with the working group's view that students must take time to write their own story without any interference from their fellow students.

The second research question was: "What are the needs of students and teachers according to the stakeholders to achieve an optimal blend between the FTFC and the online element of the course?". The working group stated it was vital to pay attention to the reciprocated fusion of the blended learning module's components. This meant that students had to focus when undertaking the online course, and pay attention in the FTFC and in peer group meetings. The study demonstrated that teachers having a protocol that assisted them in merging the different elements may help facilitate student's motivation to become engaged in the online course, with their peer groups, and in the FTFC. In sum, the teacher and fellow students could motivate the students to do their homework and PT can possibly ensure that students remain motivated while doing homework.

Czerkawski and Lyman (2016) stated that motivating students in online learning environments is a relatively new challenge in the educational field. We found that the PSD-model (Oinas-Kukkonen and Harjumaa 2009) is a useful model for developing a rich online learning course which could motivate students, according to all stakeholders. This study further demonstrated that the PSD-model was a highly practical tool for both teachers as well as instructional designers, supporting the design process at a detailed level and providing guidance on how PT techniques may be applied within online learning.

We believe it is possible for the PSD-model to be integrated in to various existing instructional design models, specifically during the design phase, such as in the ADDIE model (Branch 2009), and the E-learning Engagement Design framework of Czerkawski and Lyman (2016). The description of the 28 techniques, as shown in Tables 3, 4, 5, and 6 , can be presented to the course designers. Our descriptions of the various techniques were specific to the autobiographical course, however, with minor adaptations, it would be possible for these to be implemented in other types of educational courses too.

When a blended learning module is designed using PT, then it is recommended that the PSD-model is extended introducing a fifth category named 'Blended Learning Support'. Adding this category will ensure that conscious attention is paid to the optimal merging of the various components throughout the design process within the blended learning module. Based on our findings, two distinct techniques were established: 'role of the teacher' and 'online course versus FTFC'. We can define 'Role of the teacher' through various definitions, including: 'At the beginning of the FTFC, 
the teacher returns to the assignments made' and/or 'The teacher ensures there is sufficient coordination between the FTFC and the online course. E.g. the teacher prepares the students for the online course, such as demonstrating to them where they can find the online course and explaining some assignments' and/or 'The role of the teacher is written in a protocol'. Further, 'Online course versus FTFC' can be interpreted as: 'Interaction with the FTFC must be sufficiently stimulated within the online course. E.g. indicating that students have to take their homework to FTFC'.

Because the working group showed a great deal of diversity in the type of training with various experiences with blended education, it was not always easy to reach one shared opinion. Our results illustrated that the participatory design was able to encourage equal partnership between all of the stakeholders and multiple allocated time slots were made available for evaluation discussions, both of which benefitted the design of the course. We were able to use and learn from the experiences from each of the stakeholders, as suggested by Bovill (2014). The students, teachers and social workers felt engaged within the working group, thus stimulating the development of educational materials. Students produced a surprisingly high standard of work and insight into their prior experiences with other online modules. The instructional designers also displayed their work experience with other online modules, adding more in-depth knowledge about possible technological features. The expertise of the field's teachers and social workers further guaranteed it was possible to meet the didactic goals. Therefore, participatory design helped with focusing the content, the target group and the intrinsic motivation of the students when choices were made regarding how to use PT. To quote Burri Gram-Hansen and Ryberg (2013), we believe that our methodology allowed us to achieve 'an appropriate and adaptive balance between the technology and the context in which [it] is applied' (p. 29).

\subsection{Limitations and further research}

The working group consisted of 17 participants. In order to be more effective and to be able to organize a meeting where it was possible for all participants to be present, we would recommend establishing a smaller working group, e.g. with a maximum of ten participants. Based on our experience, the ideal composition of a working group would be: three students, two lecturers, two professional field experts, an instructional designer and an educational policy maker and, optionally, a researcher. We expect that this would lead to the same substantive choices.

Despite our positive experiences with designing a blended learning course through the PSD-model, we must be careful when interpreting our findings, as it only involves the design of one course. More research is needed and should be analyzed regarding the application of the PSD-model in higher education, such as on courses aimed at cognitive learning, or courses with a primary focus on collaborative learning. It would be interesting to determine whether the PSD-model would suggest using the same steps when undertaking the design of other blended learning courses.

The current design is part of a larger research project. In a subsequent study, we investigated the user's experience and adoption of PT, which clarify the extent to which students found the techniques motivational which were applied in the online element of the blended course (Engelbertink et al. 2020). An RCT is then carried out to investigate which design of the blended learning course has the most effect. However, previous 
research has suggested that it is difficult to distinguish which people are likely to be motivated by specific PT strategies (Van Gemert-Pijnen et al. 2018). Therefore, a recommendation for future research is to investigate, for example, which type of students are motivated by online rewards and praises, as well as analyzing students who are lack motivation from the start or throughout the duration of the course. Furthermore, it would be interesting to study whether there is a difference in what students believe will motivate them, compared to the strategies implemented which actually motivate them throughout an online course. With this kind of information, the PT techniques can be facilitated in a more tailored manner avoiding causing any frustration, increasing the student's overall motivation.

Our choice to work with an existing ICT tool - 'Articulate Storyline' - to develop the online element of the course allowed the design process to be reasonably prompt (an external software developer was not needed nor relied upon). However, the online part of the blended course that we developed was a combination of what the stakeholders wished and what the technology (Articulate Storyline software) could offer. Throughout the development of designing the online course, there was a need for more advanced ICT tools. One factor which was absent was the opportunity for the user (student) to turn PT techniques (such as rewards, praise and interaction with fellow students) on or off, at the beginning of the online module. This would fulfill the working group's wish to offer personalized online courses to students, thus preventing the PT from impeding intrinsic motivation for some students.

To conclude, this study allowed us to gain further insight into the needs and wishes of the stakeholders concerning the use of PT techniques, giving us the opportunity to develop a blended learning course specifically for social work students involving these techniques. Thus, it can be argued that the combination of PT and a participatory design would be considered recommendable for designing a blended learning course for higher education students.

Compliance with ethical standards Informed consent was obtained from all individual participants included in the study.

Conflict of interest The authors declare that they have no conflict of interest.

Open Access This article is licensed under a Creative Commons Attribution 4.0 International License, which permits use, sharing, adaptation, distribution and reproduction in any medium or format, as long as you give appropriate credit to the original author(s) and the source, provide a link to the Creative Commons licence, and indicate if changes were made. The images or other third party material in this article are included in the article's Creative Commons licence, unless indicated otherwise in a credit line to the material. If material is not included in the article's Creative Commons licence and your intended use is not permitted by statutory regulation or exceeds the permitted use, you will need to obtain permission directly from the copyright holder. To view a copy of this licence, visit http://creativecommons.org/licenses/by/4.0/.

\section{Appendix 1. 'Screenshots online course'}

Techniques shown in screenshot 1:

Category 1 Primary task support

1. Personalisation: the student fill in their name in the blue frame in the middle of the page. The computer speaks to the students with their own name during the online 
course. For example: 'Irene, in lesson 5, the teacher will look back with you on the homework of the theme Work and Care'. This comment shows also the blend between the online course and the FTFC.

2. Tunnelling: in the blue frame at the bottom right of the page you can read the instruction 'Continue reading' (in Dutch 'Ga verder'). This leads the student step by step in active form through the online course.

\section{Category 2 Dialogue support}

3. Praise: Bottom left on the page there is an audio symbol. Students get a applause when they finished the second theme.

4. In the upper right corner the students can click on the words Sources and Tips (in Dutch: Bronnen en Tips). In 'Word attachments' the student can read suggestions to make their homework on a weekly basis and in another document they get suggestions to reach more positive memories (Suggestions).

\section{Category 3 System Credibility Support}

5. Trustworthiness: In the upper left corner the logo of the institute

6. In the upper right corner the students can click on the words Sources and Tips (in Dutch: Bronnen en Tips). In 'Word attachments' the student can read about privacy policy (Surface credibility), there is some information about the authors of the method (Real-world feel), there is information about the original method of this course related to the online course (Third-party endorsements) and the sources that being used in the documents can be checked (Verifiability).

Screenshot 1 .

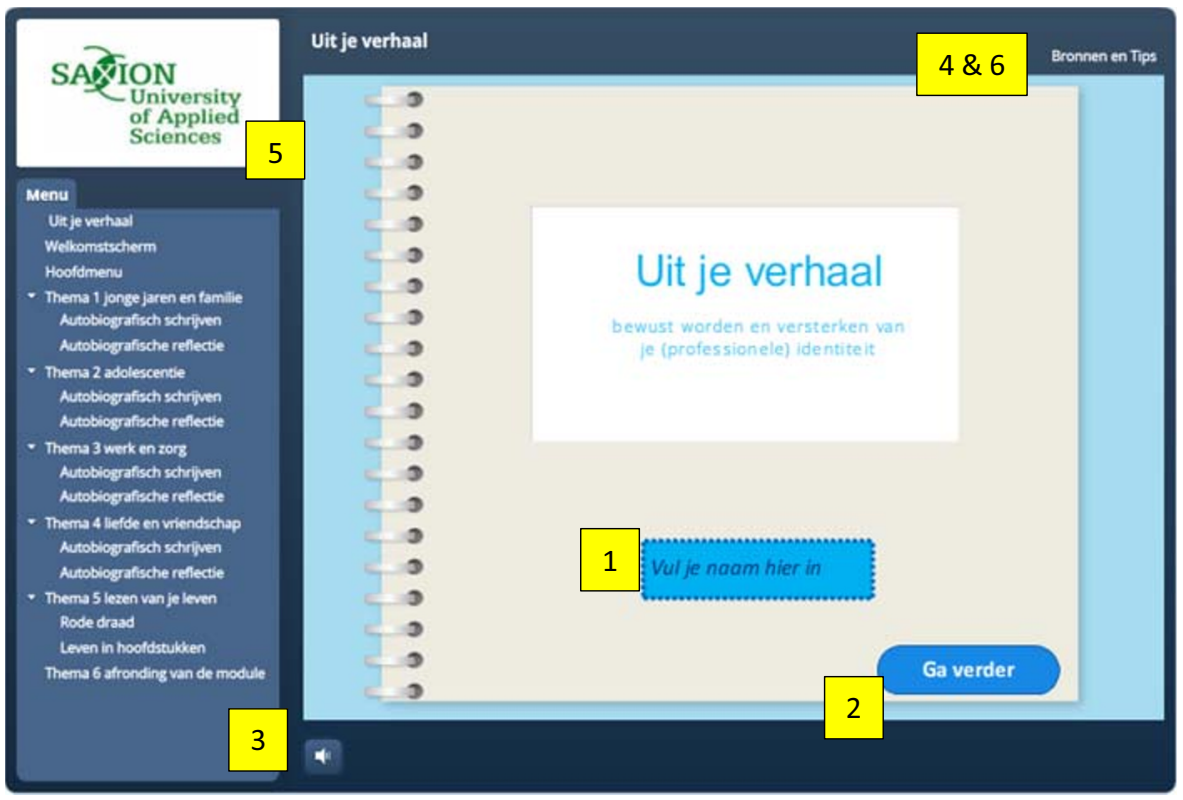


Techniques shown in screenshot 2:

Category 1 Primary task support

7. Reduction: the assignments are divided into themes (and the first four themes are divided into a writing part and a reflection part).

8. Tunnelling: Students can't go on with the next theme if they did not finish the previous one. An open or closed lock is shown that symbolizes access.

9. Self- monitoring: On the left there is a menu with an overview of all the content of the course. if the student has completed a theme, the text colour changes from black to grey.

10. Liking: The opinion of the students of the working group were decisive in the choices of the images.

Screenshot 2.

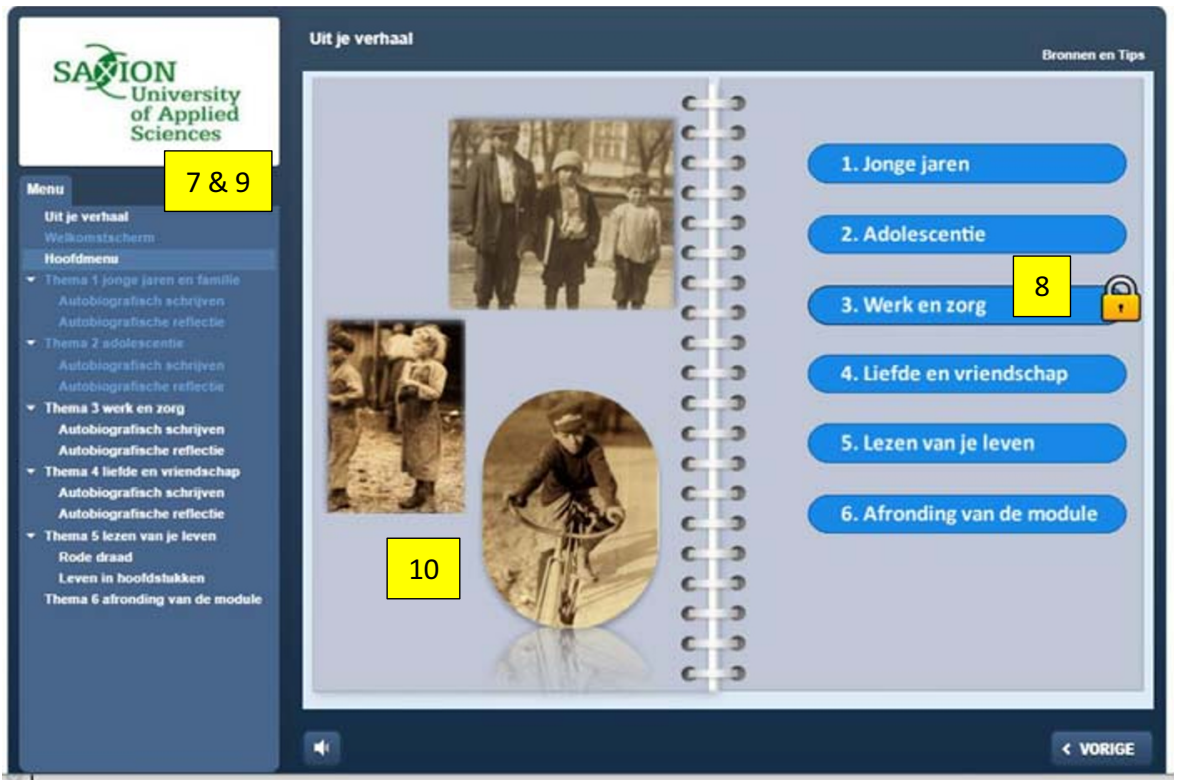

Techniques shown in screenshot 3:

Category 1 Primary task support

11. Liking: The students can think about their professional development by means of a drag exercise. 
Screenshot 3.

\section{Uit je verhaal Thema 3}

12 b. Welk component van professionele identiteit is bij jou het sterkst ontwikkeld? (sleep je antwoord in het open vakje)

zelfbeeld

zelfvertrouwen

taakopvatting

werkmotivatie

toekomstperspectief

Thema 3 werk en zorg vroog $12 b-18$

Techniques shown in screenshot 4:

Category 2 Dialogue support

12. Rewards: Students see pictures/symbols, like a star, medal, thumb when they complete a part of the online module. The symbols sometimes are shown in a short animation of $30 \mathrm{~s}$. 


\section{Screenshot 4 .}

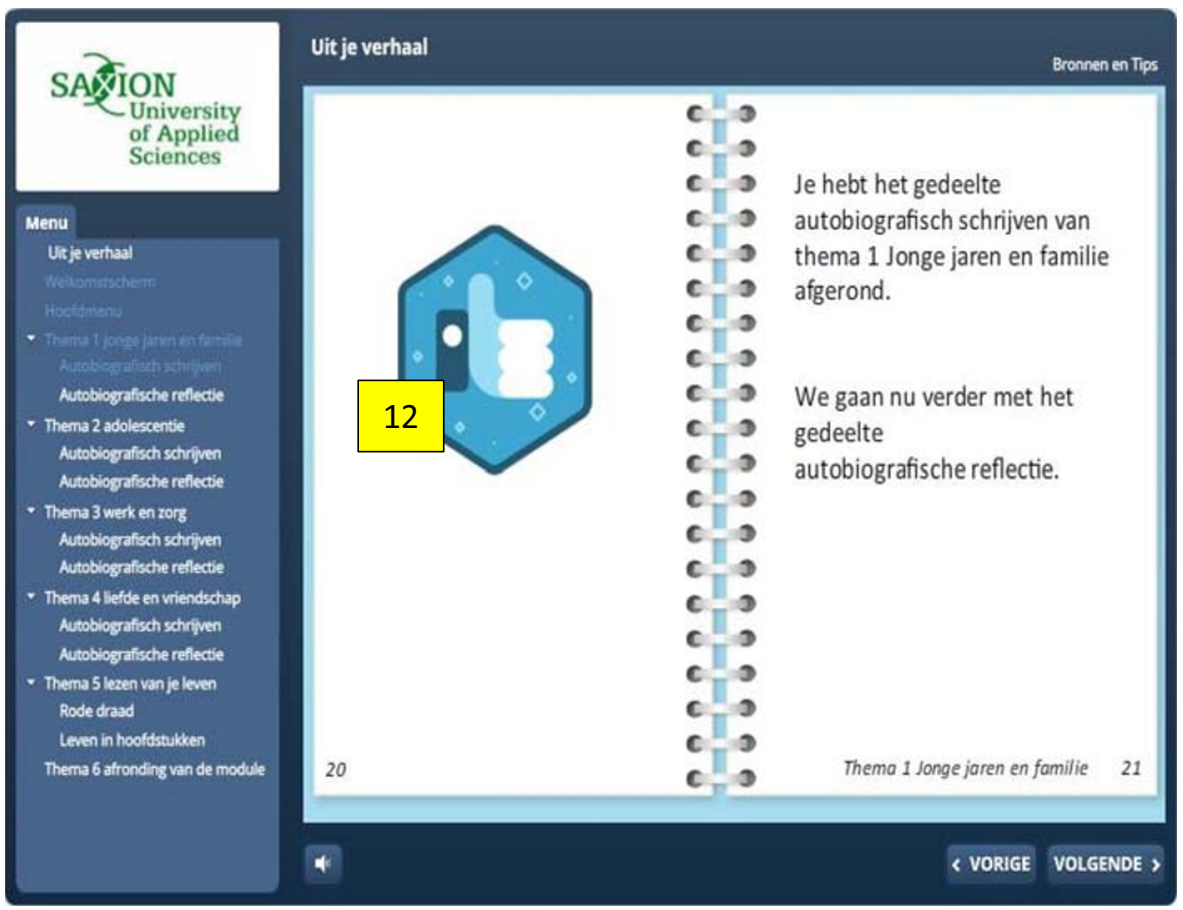

Open Access This article is licensed under a Creative Commons Attribution 4.0 International License, which permits use, sharing, adaptation, distribution and reproduction in any medium or format, as long as you give appropriate credit to the original author(s) and the source, provide a link to the Creative Commons licence, and indicate if changes were made. The images or other third party material in this article are included in the article's Creative Commons licence, unless indicated otherwise in a credit line to the material. If material is not included in the article's Creative Commons licence and your intended use is not permitted by statutory regulation or exceeds the permitted use, you will need to obtain permission directly from the copyright holder. To view a copy of this licence, visit http://creativecommons.org/licenses/by/4.0/.

\section{References}

Bano, M., \& Zowghi, D. (2015). A systematic review on the relationship between user involvement and system success. Information and Software Technology, 58, 148-169. https://doi.org/10.1016/j. infsof.2014.06.011.

Behringer, R., Burri Gram-Hansen, S., Smith, C., Soosay, M., Mikulecká, J., Winther-Nielsen, N., ... Herber, E. (2013). Persuasive technology for learning and teaching - The EuroPLOT project. In Proceedings of the International Workshop on EuroPLOT Persuasive Technology for Learning, Education and Teaching (pp. 3-7). Berlin: Springer-Verlag. Retrieved from http://eprints.leedsbeckett.ac.uk/624 /1/IWEPLET13_01_BehringerEtAl_EuroPLOT.pdf.

Bernard, R. M., Borokhovski, E., Schmid, R. F., Tamim, R. M., \& Abrami, P. C. (2014). A meta-analysis of blended learning and technology use in higher education: from the general to the applied. Journal of Computing in Higher Education, 26(1), 87-122. https://oi.org/10.1007/s12528-013-9077-3. 
Blau, I., \& Shamir-Inbal, T. (2018). Digital technologies for promoting "student voice" and co-creating learning experience in an academic course. Instructional Science, 46(2), 315-336. https://doi. org/10.1007/s11251-017-9436-y.

Bleumink, E. (2016). Trend report 2016-How technological trends enable customised education. Utrecht: SURFnet.

Bohlmeijer, E. T., \& Westerhof, G. J. (2010). Op verhaal komen, je autobiografie als bron van wijsheid. Amsterdam: Uitgeverij Boom.

Booker, A., \& Goldman, S. (2016). Participatory design research as a practice for systemic repair: doing handin-hand math research with families. Cognition and Instruction, 34(3), 222-235. https://doi.org/10.1080 /07370008.2016.1179535.

Bovill, C. (2014). An investigation of co-created curricula within higher education in the UK, Ireland and the USA. Innovations in Education and Teaching International, 51(1), 15-25. https://doi.org/10.1080 /14703297.2013.770264.

Branch, R. M. (2009). Instructional design the ADDIE. New York: Springer. https://doi.org/10.1007/978-0387-09506-6.

Bratteteig, T., \& Wagner, I. (2016). Unpacking the notion of participation in participatory design. Computer Supported Cooperative Work: CSCW: An International Journal, 25(6), 425-475. https://doi.org/10.1007 /s10606-016-9259-4.

Burri Gram-Hansen, S., \& Ryberg, T. (2013). Persuasion, learning and context adaptation. International Journal of Conceptual Structures and Smart Applications, 1(2), 28-37. https://doi.org/10.4018 /ijcssa.2013070104.

Cha, H. J., \& Ahn, M. L. (2019). Design and development of a smart-tool prototype to promote differentiated instruction: a user-centered design approach. Interactive Learning Environments, 1-17. https://doi. org/10.1080/10494820.2018.1552871.

Cober, R., Tan, E., Slotta, J., So, H. J., \& Könings, K. D. (2015). Teachers as participatory designers: two case studies with technology-enhanced learning environments. Instructional Science, 43(2), 203-228. https://oi.org/10.1007/s11251-014-9339-0.

Czerkawski, B. C., \& Lyman, E. W. (2016). An instructional design framework for fostering student engagement in online learning environments. TechTrends, 60(6), 532-539. https://doi.org/10.1007 /s11528-016-0110-z.

de Jong, N., Savin-Baden, M., Cunningham, A. M., \& Verstegen, D. M. L. (2014). Blended learning in health education: three case studies. Perspectives on Medical Education, 3, 278-288. https://doi.org/10.1007 /s40037-014-0108-1.

Devincenzi, S., Kwecko, V., De Toledo, F. P., \& Mota, F. P. (2017). Persuasive technology: Applications in education. In Proceedings-Frontiers in Education Conference, FIE (pp. 1-7). Indianapolis: Institute of Electrical and Electronics Engineers Inc.. https://doi.org/10.1109/FIE.2017.8190439.

Engelbertink, M. M. J. (2015a). Evaluaties autobiografisch onderzoek Minor Spirit 2012 - 2015. Enschede: Saxion, University of Applied Sciences.

Engelbertink, M. M. J. (2015b). Naar een nieuwe professionele identiteit. Enschede: Saxion, University of Applied Sciences.

Engelbertink, M. M. J., Kelders, S. M., Woudt-, K. M., \& Westerhof, G. J. (2020). Evaluating the value of persuasive technology and the role of teachers in a blended learning course for social work students. Social Work Education, 1-17. https://doi.org/10.1080/02615479.2020.1715935.

Fogg, B. J. (2003). Captology: Looking forward. In Persuasive technology, using computers to change what we think and do (pp. 241-253). https://doi.org/10.1016/B978-155860643-2/50012-3.

Frauenberger, C., Good, J., Fitzpatrick, G., \& Iversen, O. S. (2015). In pursuit of rigour and accountability in participatory design. International Journal of Human Computer Studies, 74, 93-106. https://doi. org/10.1016/j.ijhcs.2014.09.004.

Garrison, D. R., \& Kanuka, H. (2004). Blended learning: uncovering its transformative potential in higher education. Internet and Higher Education, 7(2), 95-105. https://doi.org/10.1016/j.iheduc.2004.02.001.

Henrie, C. R., Halverson, L. R., \& Graham, C. R. (2015). Measuring student engagement in technologymediated learning: a review. Computers \& Education, 90, 36-53. https://doi.org/10.1016/j. compedu.2015.09.005.

Holley, D., \& Oliver, M. (2010). Student engagement and blended learning: portraits of risk. Computers \& Education, 54(3), 693-700. https://doi.org/10.1016/j.compedu.2009.08.035.

Keengwe, J., \& Kang, J. J. (2013). A review of empirical research on blended learning in teacher education programs. Education and Information Technologies, 18(3), 479-493. https://doi.org/10.1007/s10639-0119182-8. 
Kelders, S. M., Kulyk, O. A., Van Gemert-Pijnen, L., \& Oinas-Kukkonen, H. (2015). Selecting effective persuasive strategies in behavior change support systems. In S. M. Kelders, O. A. Kulyk, L. Van GemertPijnen, \& H. Oinas-Kukkonen (Eds.), Proceedings of the third international workshop on behavior change support systems (pp. 1-6). CEUR.org.

Kiviniemi, M. T. (2014). Effects of a blended learning approach on student outcomes in a graduate-level public health course. BMC Medical Education, 14, 47. https://doi.org/10.1186/1472-6920-14-47.

Könings, K. D., \& McKenney, S. (2017). Participatory design of (built) learning environments. European Journal of Education, 52(3), 247-252. https://doi.org/10.1111/ejed.12232.

Korte, J., Bohlmeijer, E. T., Cappeliez, P., Smit, F., \& Westerhof, G. J. (2012). Life review therapy for older adults with moderate depressive symptomatology: A pragmatic randomized controlled trial. Psychological Medicine, 42(6), 1163-1173. https://doi.org/10.1017/S0033291711002042.

Lam, J. (2014). The context of blended learning: The TIPS blended learning model. In S. K. S. Cheung, J. Fong, J. Zhang, R. Kwan, \& L. F. Kwok (Eds.), Hybrid learning. Theory and practice. ICHL 2014. Lecture notes in computer science (Vol. 8595, pp. 80-92). Cham: Springer. https://doi.org/10.1007/978-3319-08961-4_9.

Lamers, S. M. A. A., Bohlmeijer, E. T., Korte, J., \& Westerhof, G. J. (2015). The efficacy of life-review as online-guided self-help for adults: A randomized trial. Journals of Gerontology - Series B Psychological Sciences and Social Sciences, 70(1), 24-34. https://oi.org/10.1093/geronb/gbu030.

López-Pérez, M. V., Pérez-López, M. C., \& Rodríguez-Ariza, L. (2011). Blended learning in higher education: students' perceptions and their relation to outcomes. Computers \& Education, 56(3), 818-826. https://doi. org/10.1016/j.compedu.2010.10.023.

López-Pérez, M. V., Pérez-López, M. C., Rodríguez-Ariza, L., \& Argente-Linares, E. (2013). The influence of the use of technology on student outcomes in a blended learning context. Educational Technology Research and Development, 61(4), 625-638. https://doi.org/10.1007/s11423-013-9303-8.

Lowell Bishop, J., \& Verleger, M. (2013). The flipped classroom: A survey of the research. In Proceedings of the Annual Conference of the American Society for Engineering Education (pp. 1-18). Atlanta. https://doi.org/10.1109/FIE.2013.6684807.

Ma, J., Han, X., Yang, J., \& Cheng, J. (2015). Examining the necessary condition for engagement in an online learning environment based on learning analytics approach: the role of the instructor. The Internet and Higher Education, 24, 26-34. https://doi.org/10.1016/j.iheduc.2014.09.005.

McNaught, C., Lam, P., \& Cheng, K. F. (2012). Investigating relationships between features of learning designs and student learning outcomes. Educational Technology Research and Development, 60(2), 271286. https://doi.org/10.1007/s11423-011-9226-1.

Mintz, J., \& Aagaard, M. (2012). The application of persuasive technology to educational settings. Educational Technology Research and Development, 60(3), 483-499. https://doi.org/10.1007/s11423012-9232-y.

Monk, E. F., Guidry, K. R., Pusecker, K. L., \& Ilvento, T. W. (2020). Blended learning in computing education: it's here but does it work? Education and Information Technologies, 25, 83-104. https://doi. org/10.1007/s10639-019-09920-4.

Ng, K. H., Bakri, A., \& Rahman, A. A. (2016). Effects of persuasive designed courseware on children with learning difficulties in learning Malay language subject. Education and Information Technologies, 21(5), 1413-1431. https://doi.org/10.1007/s10639-015-9391-7.

Oinas-Kukkonen, H., \& Harjumaa, M. (2009). Persuasive Systems Design: key issues, process model, and system features. Communications of the Association for Information Systems, 24(Article 28), 485-500.

Ruland, C. M., Starren, J., \& Vatne, T. M. (2008). Participatory design with children in the development of a support system for patient-centered care in pediatric oncology. Journal of Biomedical Informatics, 41(4), 624-635. https://doi.org/10.1016/j.jbi.2007.10.004.

Sanders, E. B.-N., \& Stappers, P. J. (2008). Co-creation and the new landscapes of design. CoDesign, 4(1), 518. https://doi.org/10.1080/15710880701875068.

Santa-Rosa, J. G. (2012). Participatory design in the project of virtual learning environment of histology. Work, 41(Supplement 1), 1157-1159. https://doi.org/10.3233/WOR-2012-0296-1157.

Schneider, M., \& Preckel, F. (2017). Variables associated with achievement in higher education: a systematic review of meta-analyses. Psychological Bulletin, 143(6), 565-600.

Simonsen, J., \& Hertzum, M. (2012). Sustained participatory design: extending the iterative approach. Design Issues, 28(3), 10-21. https://doi.org/10.1162/DESI a 00158.

Song, D., \& Oh, E. Y. (2016). A participatory design approach for a mobile app-based personal response system. Journal of Educational Technology Systems, 44(3), 346-361. https://doi.org/10.1177 $/ 0047239515618465$. 
Søraker, J. H. (2015). In J. H. Søraker, J.-W. van der Rijt, J. de Boer, P.-H. Wong, \& P. Brey (Eds.), Well-being in contemporary society. Cham: Springer International Publishing. https://doi.org/10.1007/978-3-31906459-8.

Spector-Mersel, G. (2016). Life story reflection in social work education: a practical model. Journal of Social Work Education, 53(2), 1-14. https://doi.org/10.1080/10437797.2016.1243498.

Uğur, B., Akkoyunlu, B., \& Kurbanoğlu, S. (2011). Students' opinions on blended learning and its implementation in terms of their learning styles. Education and Information Technologies, 16(1), 5-23. https://doi.org/10.1007/s10639-009-9109-9.

Van Gemert-Pijnen, J. E. W. C., Nijland, N., van Limburg, M., Ossebaard, H. C., Kelders, S. M., Eysenbach, G., \& Seydel, E. R. (2011). A holistic framework to improve the uptake and impact of eHealth technologies. Journal of Medical Internet Research, 13(4). https://doi.org/10.2196/jmir.1672.

Van Gemert-Pijnen, J. E. W. C., Kelders, S. M., \& Bohlmeijer, E. T. (2014). Understanding the usage of content in a mental health intervention for depression: An analysis of log data. Journal of Medical Internet Research, 16(1), e27. https://doi.org/10.2196/jmir.2991.

Van Gemert-Pijnen, J. E. W. C., Kelders, S. M., \& Beerlage - De Jong, N., \& Oinas - Kukkonen, H. (2018). Persuasive health technology. In J. E. W. C. Van Gemert-Pijnen, S. M. Kelders, H. Kip, \& R. Sanderman (Eds.), eHealth research, theory and development, a multidisciplinary approach (p. 344). Routledge.

Vo, H. M., Zhu, C., \& Diep, N. A. (2017). The effect of blended learning on student performance at courselevel in higher education: a meta-analysis. Studies in Educational Evaluation, 53, 17-28. https://doi. org/10.1016/j.stueduc.2017.01.002.

Westerhof, G. J., Lamers, S. M. A., Postel, M. G., \& Bohlmeijer, E. T. (2017). Online therapy for depressive symptoms: An evaluation of counselor-led and peer-supported life review therapy. The Gerontologist. https://doi.org/10.1093/geront/gnx140

Publisher's note Springer Nature remains neutral with regard to jurisdictional claims in published maps and institutional affiliations.

\title{
Affiliations
}

\section{Monique M. J. Engelbertink ${ }^{1,2} \cdot$ Saskia M. Kelders ${ }^{2,3} \cdot$ Kariene $M$. Woudt-Mittendorff ${ }^{1}$ • Gerben J. Westerhof ${ }^{2}$}

\author{
Saskia M. Kelders \\ s.m.kelders@utwente.nl \\ Kariene M. Woudt-Mittendorff \\ k.m.mittendorff@saxion.nl \\ Gerben J. Westerhof \\ g.j.westerhof@utwente.nl
}

1 Saxion University of Applied Sciences, Handelskade 75, 7417 DH Deventer, the Netherlands

2 University of Twente, P.O. Box 217, 7500 AE Enschede, the Netherlands

3 Optentia Research Focus Area, North West University, Vanderbijlpark, South Africa 